\title{
PENURUNAN SKALA NYERI SENDI SETELAH DIBERIKAN SENAM YOGA PADA LANSIA
}

\author{
Indry Yani Shaphira1 ${ }^{1}$ Ricky Riyanto Iksan ${ }^{2 *}$, Sri Atun Wahyuningsih ${ }^{3}$ \\ Akademi Keperawatan Pelni Jakarta \\ Email Korespondensi: Indryvira05@gmail.com
}

Disubmit: 17 Oktober 2021 Diterima: 05 Desember 2021 Diterbitkan: 01 Januari 2022 DOI: https://doi.org/10.33024/mnj.v1i1.5323

\section{ABSTRACT : DECREASE IN JOINT PAIN SCALE AFTER BEING GIVEN YOGA EXERCISE TO THE ELDERLY}

Background: The problem of joint pain in the elderly (elderly) is quite high with increasing age, including those who experience joint pain problems due to physical changes.

Purpose: This study aims to identify the effect of yoga on joint pain in the elderly. Research Methods: This type of research is a case study design research, which is aform of research (inquiry) or case studies and interventions about a problem that has aspecificity (particularity).

Results: The results of this study were that there was a change in the pain scale in the elderly with joint pain after being given yoga exercise therapy, before being given therapy the pain scale value was 4 currently, after yoga exercise therapy the scalevalue became 3 light based on these results indicating that there was a significant decrease.

Conclusion: The conclusion of this study is that the application of yoga exercise therapyintervention has an effect on changes in pain scale, as evidenced by data on the characteristics of joint pain sufferers, namely age, gender and activities such as factors that rarely exercise and do not repeat therapy. pain scale in patients with joint pain.

Keywords : Ederly; joint pain; yoga exercise

\section{INTISARI: PENURUNAN SKALA NYERI SENDI SETELAH DIBERIKAN SENAM YOGA PADA LANSIA}

Latar Belakang : Masalah nyeri sendi pada lanjut usia (lansia) cukup tinggi dengan bertambahnya usia lansia termasuk golongan yang mengalami masalah nyeri sendi akibat perubahan fisik.

Tujuan : Penelitian ini bertujuan untuk teridentifikasi adanya pengaruh yoga dengan nyeri sendi pada lansia.

Metode Penelitian : Jenis penelitian ini adalah penelitian case study design yaitu suatubentuk penelitian (inquiry) atau studi kasus dan intervensi tentang suatu masalah yang memiliki sifat kekhususan (particularity).

Hasil: Hasil penelitian pada 4 responden yang dilakukan mengalami perubahan skala nyeri pada lansia nyeri sendi setelah diberikan therapy senam yoga, sebelum 
diberikan terapi nilai skala nyeri 4 sedang, setelah dilakukan terapi senam yoga nilai skalamenjadi 3 ringan berdasarkan hasil tersebut menunjukkan bahwa terjadi penurunan yang signifikan.

Kesimpulan : Kesimpulan dari penelitian ini penerapan intervensi therapy senam yoga berpengaruh terhadap perubahan skala nyeri, dibuktikan dengan data karakteristik penderita nyeri sendi yaitu usia, jenis kelamin dan aktivitas seperti faktor jarang berolahraga dan tidak terapi berulang, hal ini menunjukkan semakin sering melakukan terapi senam yoga dapat mempengaruhi penilaian skala nyeri pada penderita nyeri sendi.

Kata Kunci : Lansia; Nyeri Sendi; Senam Yoga

\section{PENDAHULUAN}

Nyeri sendi merupakan penyakit tipe paling umum dari penyakit radang sendi lainnya dan dijumpai khusus pada orang lanjut usia atau sering disebut penyakit degeneratif. Penuaan atau proses terjadinya tua adalah suatu proses menghilangnya secara perlahan - lahan kemampuan jaringan untuk memperbaiki diri dan mempertahankan fungsi normalnya, sehingga tidak dapat bertahan terhadap infeksi serta memperbaiki kerusakan yang dideritanya, sehingga seiring dengan proses menua tersebut seseorang akan mudah mengalami penyakit degeneratif. Menurut World Health Organization (WHO, 2018) penderita nyeri sendi menurun 15\% menjadi 128 jiwa diseluruh dunia. World Health Organization (WHO, 2016) mencatat di Indonesia jumlah populasi penderita gangguan sendi mencapai hingga $81 \%$.

Prevalensi penyakit sendi di Indonesia pada tahun 2018 berdasarkan diagnosis dokter pada usia 55-64 tahun yaitu 15,5\%, pada usia $65-74$ yaitu $18,6 \%$ dan paling banyak penduduk yang berusia 75+ yaitu $18,9 \%$. Prevalensi pada tahun 2018 berdasarkan diagnosis dokter penduduk yang mengalami penyakit sendi terbanyak berada di provinsi Aceh yaitu sekitar 13,3\%. Sedangkan provinsi dengan penduduk masalah nyeri sendi terendah berada di provinsi Sulawesi Barat yaitu sekitar $3,2 \%$. Di DKI Jakarta sendiri penduduk yang mengalami masalah sendi berdasarkan diagnosis dokter sekitar 7,1\%. (Kementerian Kesehatan Republik Indonesi tahun 2018). Tabda dan gejala nyeri sendi yaitu menurunnya kemampuan muskuloskeletal menyebabkan terjadinya perubahan secara degeneratif yang dirasakan adanya nyeri, kekakuan, hilangnya gerakan dan tanda-tanda inflamasi seperti nyeri tekan, yang disertai dengan pembengkakan yang mengakibatkan gangguan mobilitas. Adapun faktor dari penyakit ini adalah mekanisme imunitas, faktor metabolik, faktor genetic dan pemicu lingkungan, faktor usia. (Solehati, 2015).

Upaya pencegahan dan penanggulangan nyeri sendi telah dilakukan berbagai upaya oleh Kementerian Kesehatan Republik Indonesia, yaitu dilakukan dengan peningkatan perilaku hidup sehat, kualitas lingkungan, edukasi hidup sehat, penyediaanpangan sehat serta percepatan perbaikan gizi pelaksanaannya.

Intervensi senam yoga yaitu salah satu upaya terapi yang efektif dan aman untuk meningkatkan aktifitas fisik.yoga memiliki banyak manfaat 
antara lain; dapat meningkatkan imunitas tubuh, meningkatkan keseimbangan energi, meningkatkan daya ingat dan konsentrasi, membuat otot tubuh lebih luntur, menjadikan kondisi tubuh kebih baik, menguatkan tulang mengurangi kecemasan dan mengobati tubuh dari berbagai keluhan yang salah satunya adalah nyeri sendi.

Hasil penelitian yang dilakukan Faradillah Fenty, (2019)yang berjudul pengaruh senam yoga terhadap tingkat nyeri rheumatoid arthritis pada lansia di desa sawiji kecamatan jogoroto kabupaten jombang dengan jumlah sample 38 orang. Hasil penelitian menunjukkan bahwa sebelum diberikan senam yoga hampir seluruhnya $(92,1 \%)$ atau 35 responden mengalami nyeri berat dan setelah melakukan senamyoga 19 responden merasakan nyeri ringan.

Hasil penelitain yang dilakukan Wulandari N.A, (2016) yang berjudul pengaruh yoga terhadap nyeri sendi pada lansia di Pslu Blitar. Dengan jumlah sample 10 lansia. Hasil penelitian ini sebelum lansia mengikuti senamyoga $80 \%$ merasakan nyeri sendi dengan skala sedang setelah mengikuti yoga $50 \%$ lansia merasakan rasa nyeri sendi nya berkurang.

Hasil penelitain yang dilakukan Nugroho \& Sari, (2016)yang berjudul senam yoga untuk intensitas nyeri pada penderita osteoarthritis di Wilayah Kerja Puskesmas Babat Lamongan masyarakat yang belum melakukan senam yoga rata-rata intesitas nyeri 4,9 dan etelah melakukan senam yoga rata-rata nyeri 3,8 sehingga mengalami rata-rata penurunan 1,1. Dari hasil studi pendahuluan yang dilkaukan di wilayah Puskesmas Kelurahan Kedoya Selatan Kecamatan Kebon Jeruk sebanyak 188.100 jiwa dengan penderita nyeri sendi sebanyak 50 jiwa. Data hasil survey di wilayah RW.01 Kelurahan Kedoya Selatan Kecamatan Kebon Jeruk Jakarta Barat pada Bulan November sampai Desember 2020 terdapat 17 jiwa yang menderita nyeri sendi Berdasarkan uraian diatas peneliti tertarik untuk menyusun dan menganalisa bagaimana “Intervensi Therapy Senam Yogaterhadap Perubahan Skala Nyeripada Lansia dengan Nyeri Sendi

\section{METODE}

Jenis penelitian ini adalah penelitian case study design yaitu suatu bentuk penelitian (inquiry) atau studi kasus dan intervensitentang suatu masalah yang memiliki sifat kekhususan (particularity) dengan tujuan untuk mempelajari secara intensif unit- unit sosial seperti perhimpunan, perorangan maupun kelompok, keluarga dan bahkan masyarakat luas. Pada penelitian ini peneliti melakukan intervensi terapi senam yoga pada empat lansia dengan

\section{HASIL}

Karakteristik Responden Wilayah Kelurahan Kedoya Selatan Jakarta Barat".

nyeri sendi yaitu keempat penderita sama- sama diberikan terapi senam yoga.

Penelitimelakukan intervensi terapi senam yoga terhadap perubahan skala nyeri pada lansia dengan nyeri sendi dengan karakteristik yang sama yaitu 4 klien sama - sama diberikan terapi senam yoga dilakukan selama 30 menit, setiap $3 x$ selama seminggu. 
Tabel 1

Distribusi Karakteristik Responden $(n=4)$ dengan Skala Nyeri Sendi Sebelum diberikanIntervensi Therapy Senam Yoga di Rw 01 Kelurahan Kedoya Selatan Kecamatan Kebon Jeruk Jakarta Barat 2021

\begin{tabular}{lccc}
\hline Responden & Usia & Jenis Kelamin & $\begin{array}{c}\text { Skala } \\
\text { Nyeri Sendi }\end{array}$ \\
\hline Responden 1 & 60 Tahun & Perempuan & 6 \\
Responden 2 & 66 Tahun & Perempuan & 6 \\
Responden 3 & 62 Tahun & Perempuan & 6 \\
Responden 4 & 60 Tahun & Perempuan & 6 \\
\hline
\end{tabular}

Berdasarkan tabel 1 sesuai dengan jurnal rujukan utama yang dipakai kriteria inklusi dari responden adalah lansia berusia 55 70 (elderly), penderita bersedia menjadi responden. Skala nyeri sendi pada lansia menunjukan bahwa responden sudah dengan skala nyeri sedang, selama melakukan intervensi dan implementasi lansia sangat kooperatif.

Pelaksanaan Intervensi dan Implementasi Keperawatan :

a. Hasil Penerapan Pertama

Tabel 2

Skala Nyeri Sendi karakteristik Responden $(n=4)$ Sebelum danSesudah Pemberian Therapy Senam Yoga di Rw 01 KelurahanKedoya Selatan Kecamatan Kebon Jeruk Jakarta Barat 2021

\begin{tabular}{ccccc}
\hline & Responden & $\begin{array}{c}\text { Sebelum } \\
\text { Therapy } \\
\text { Senam Yoga }\end{array}$ & $\begin{array}{c}\text { Sesudah } \\
\text { Therapy } \\
\text { Senam Yoga }\end{array}$ & \multicolumn{1}{c}{ Keterangan } \\
\cline { 1 - 3 } Senin, 19 Juli & $\begin{array}{c}\text { Responden 1 } \\
\text { Pukul 09.00 }\end{array}$ & 6 & 6 & $\begin{array}{l}\text { Nyeri, tidak ada } \\
\text { penurunan }\end{array}$ \\
Pertemuan 1 & $\begin{array}{c}\text { Responden 2 } \\
\text { Pukul 10.10 }\end{array}$ & 6 & 6 & $\begin{array}{l}\text { Nyeri, tidak ada } \\
\text { penurunan }\end{array}$ \\
& $\begin{array}{c}\text { Responden 3 } \\
\text { Pukul 11.15 }\end{array}$ & 6 & 6 & $\begin{array}{l}\text { Nyeri, tidak ada } \\
\text { penurunan }\end{array}$ \\
& $\begin{array}{l}\text { Responden 4 } \\
\text { Pukul 12.30 }\end{array}$ & 6 & 6 & $\begin{array}{l}\text { Nyeri, tidak ada } \\
\text { penurunan }\end{array}$ \\
\cline { 1 - 2 } & & & &
\end{tabular}

\section{Sumber : Data Primer, 2021}

Hasil table 2 diatas menunjukan bahwa dari 4 responden sebelum therapy senam yoga pengukuran nilai pengukuran skala nyeri sendi ratarata diatas 5 . Setelah dilakukan therapy senam yoga tidak mengalami penurunan yang signifikan skala nyeri sendi dan nyeri masih ada pada hari pertama. 
b. Hasil Penerapan Kedua

Tabel 3

Skala Nyeri Sendi karakteristik Responden $(n=4)$ Sebelum dan SesudahTherapy

Senam Yogadi Rw 01 Kelurahan Kedoya Selatan

Kecamatan Kebon Jeruk Jakarta Barat 2021

\begin{tabular}{|c|c|c|c|c|}
\hline & Responden & $\begin{array}{c}\text { Sebelum } \\
\text { Therapy } \\
\text { Senam Yoga }\end{array}$ & $\begin{array}{c}\text { Sesudah } \\
\text { Therapy } \\
\text { Senam } \\
\text { Yoga }\end{array}$ & Keterangan \\
\hline $\begin{array}{l}\text { Rabu, } 21 \text { Juli } \\
2021\end{array}$ & $\begin{array}{l}\text { Responden } 1 \\
\text { Pukul } 09.00\end{array}$ & 6 & 6 & $\begin{array}{l}\text { Nyeri masihtidak ada } \\
\text { penurunan }\end{array}$ \\
\hline $\begin{array}{l}\text { Pertemuan } \\
\quad 2\end{array}$ & $\begin{array}{l}\text { Responden } 2 \\
\text { Pukul } 10.10\end{array}$ & 6 & 6 & $\begin{array}{c}\text { Nyeri } \\
\text { tidak ada penurunan }\end{array}$ \\
\hline & $\begin{array}{l}\text { Responden } 3 \\
\text { Pukul } 11.15\end{array}$ & 6 & 6 & $\begin{array}{l}\text { Nyeri masih tidak ada } \\
\text { penurunan }\end{array}$ \\
\hline
\end{tabular}

Responden 4

Pukul 12.30

6

Nyeri masih idak ada penurunan

\section{Sumber : Data Primer, 2021}

Hasil table 3 menunjukan bahwa dari 4 responden sebelum therapy senam yogapengukuran skala nyeri sendi rata-rata diatas 5 .

\section{c. Hasil Penerapan Ketiga}

Tabel 4

Skala Nyeri Sendi karakteristik Responden $(n=4)$ Sebelum dan Sesudah Therapy

Senam Yogadi Rw 01 Kelurahan Kedoya Selatan Kecamatan Kebon Jeruk Jakarta

\begin{tabular}{ccccc}
\hline & Responden & $\begin{array}{c}\text { Sebelum } \\
\text { Therapy } \\
\text { Senam Yoga }\end{array}$ & $\begin{array}{c}\text { Sesudah } \\
\text { Therapy } \\
\text { Senam Yoga }\end{array}$ & Keterangan \\
\hline $\begin{array}{c}\text { Sabtu, 24 } \\
\text { Juli 2021 }\end{array}$ & $\begin{array}{c}\text { Responden 1 } \\
\text { Pukul 09.00 }\end{array}$ & 6 & 5 & $\begin{array}{c}\text { Nyeri berkurang } \\
\text { Turun }\end{array}$ \\
$\begin{array}{c}\text { Pertemuan } \\
3\end{array}$ & $\begin{array}{c}\text { Responden 2 } \\
\text { Pukul 10.15 }\end{array}$ & 6 & 6 & $\begin{array}{c}\text { Nyeri masih ada } \\
\text { Tetap }\end{array}$ \\
$\begin{array}{c}\text { Responden 3 } \\
\text { Pukul 11.15 }\end{array}$ & 6 & 5 & $\begin{array}{c}\text { Nyeri masih ada } \\
\text { Turun }\end{array}$
\end{tabular}


Responden 4

Pukul 12.30

6

5

Nyeri masih ada

Turun

\begin{tabular}{ll}
\hline & Sumber : Data Primer, 2021 \\
Hasil table 4 diatas & responden 1 yang mengalami \\
menunjukan bahwa dari 4 responden & 5 , responden 3 mengalami penurunan \\
sebelum therapy senam yoga & skala nyeri dari 6 menjadi 5 dan \\
pengukuran nilai pengukuran skala & responden 4 mengalami penurunan \\
nyeri rerata diatas 5 . Setelah & skala nyeri dari 6 menjadi 5 nyeri \\
dilakukan therapy senam yoga & masih ada pada hari ketiga.
\end{tabular}

d. Hasil Penerapan Keempat

Tabel 5

Skala Nyeri Sendi karakteristik Responden $(n=4)$ Sebelum dan Sesudah Pemberian Therapy Senam Yoga di Rw 01 Kelurahan Kedoya Selatan Kecamatan Kebon Jeruk Jakarta Barat 2021

\begin{tabular}{|c|c|c|c|c|}
\hline & Responden & $\begin{array}{c}\text { Sebelum } \\
\text { Therapy } \\
\text { Senam Yoga }\end{array}$ & $\begin{array}{c}\text { Sesudah } \\
\text { Therapy } \\
\text { Senam Yoga }\end{array}$ & Keterangan \\
\hline $\begin{array}{l}\text { Senin, } 26 \text { Juli } \\
2021\end{array}$ & $\begin{array}{l}\text { Responden } 1 \\
\text { Pukul } 09.00\end{array}$ & 6 & 5 & $\begin{array}{c}\text { Nyeri masih ada } \\
\text { Turun }\end{array}$ \\
\hline Pertemuan & Responden 2 & & & Nyeri masih ada \\
\hline 4 & Pukul 10.10 & 6 & 5 & Turun \\
\hline & $\begin{array}{l}\text { Responden } 3 \\
\text { Pukul } 11.15\end{array}$ & 6 & 6 & $\begin{array}{c}\text { Nyeri masih ada } \\
\text { Tetap }\end{array}$ \\
\hline & $\begin{array}{l}\text { Responden } 4 \\
\text { Pukul } 12.20\end{array}$ & 6 & 5 & $\begin{array}{c}\text { Nyeri masih ada } \\
\text { Turun }\end{array}$ \\
\hline
\end{tabular}

Sumber : Data Primer, 2021

Hasil table tabel 5 diatas menunjukan bahwa dari 4 responden sebelum therapy senam yoga pengukuran skala nyeri rerata diatas 5. Setelah dilakukan therapy senam yoga responden 1 yang mengalami penurunan skala nyeri dari 6 menjadi
5, responden

2 mengalami penurunan skala nyeri sendi dari 6 menjadi 5 dan responden 4 mengalami penurunan dari 6 menjadi 5 nyeri masih ada pada hari keempat. 
e. Hasil Penerapan Kelima

Tabel 6

Skala Nyeri Sendi karakteristik Responden $(n=4)$ Sebelum dan SesudahTherapy Senam Yogadi Rw 01 Kelurahan

Kedoya Selatan Kecamatan Kebon Jeruk Jakarta Barat 2021

\begin{tabular}{lcccc}
\hline & Responden & $\begin{array}{c}\text { Sebelum } \\
\text { Therapy } \\
\text { Senam Yoga }\end{array}$ & $\begin{array}{c}\text { Sesudah } \\
\text { Therapy } \\
\text { Senam Yoga }\end{array}$ & Keterangan \\
\hline $\begin{array}{l}\text { Rabu, 28 Juli } \\
2021\end{array}$ & $\begin{array}{c}\text { Responden 1 } \\
\text { Pukul 09.00 }\end{array}$ & 5 & 4 & $\begin{array}{c}\text { Nyeri berkurang } \\
\text { Turun }\end{array}$ \\
$\begin{array}{c}\text { Pertemuan } \\
5\end{array}$ & $\begin{array}{c}\text { Responden 2 } \\
\text { Pukul 10.10 }\end{array}$ & 5 & 5 & $\begin{array}{c}\text { Nyeri masih ada } \\
\text { Tetap }\end{array}$ \\
& $\begin{array}{c}\text { Responden 3 } \\
\text { Pukul 11.15 }\end{array}$ & 5 & 5 & $\begin{array}{c}\text { Nyeri masih ada } \\
\text { Tetap } \\
\text { Responden 4 } \\
\text { Pukul 12.20 }\end{array}$ \\
\end{tabular}

Sumber : Data Primer, 2021

Berdasarkan tabel 4.6 diatas menunjukan bahwa dari 4 responden sebelum therapy senam yoga pengukuran skala nyeri sendi rerata 5 . Setelah dilakukan therapy senam yoga responden 1 yang mengalami penurunan skala nyeri dari 5 menjadi 4 dan responden 4 mengalami penurunan skala nyeri dari 5 menjadi 4 masih ada pada hari kelima.

\section{f. Hasil Penerapan Keenam}

Tabel 7

Skala Nyeri Sendi karakteristik Responden $(n=4)$ Sebelum dan SesudahTherapy Senam Yoga di Rw 01 Kelurahan Kedoya Selatan

Kecamatan Kebon Jeruk Jakarta Barat 2021

\begin{tabular}{ccccc}
\hline & Responden & $\begin{array}{c}\text { Sebelum } \\
\text { Therapy } \\
\text { Senam Yoga }\end{array}$ & $\begin{array}{c}\text { Sesudah } \\
\text { Therapy } \\
\text { Senam Yoga }\end{array}$ & Keterangan \\
\hline $\begin{array}{c}\text { Sabtu, 31 Juli } \\
\text { 2021 }\end{array}$ & $\begin{array}{c}\text { Responden 1 } \\
\text { Pukul 09.00 }\end{array}$ & 5 & 4 & $\begin{array}{c}\text { Nyeri berkurang } \\
\text { Turun }\end{array}$ \\
$\begin{array}{c}\text { Pertemuan } \\
6\end{array}$ & $\begin{array}{c}\text { Responden 2 } \\
\text { Pukul 10.10 }\end{array}$ & 5 & 4 & $\begin{array}{c}\text { Nyeri masih ada } \\
\text { Turun }\end{array}$ \\
& $\begin{array}{c}\text { Responden 3 } \\
\text { Pukul 11.15 }\end{array}$ & 5 & 4 & $\begin{array}{c}\text { Nyeri masih ada } \\
\text { Turun }\end{array}$
\end{tabular}


Responden 4

Pukul 12.30

5

4

Nyeri masih ada

Turun

Sumber : Data Primer, 2021

Hasil table 7 diatas menunjukan bahwa dari 4 responden sebelum therapy senam yoga pengukuran skala

nyeri sendi rerata 5. Setelah dilakukan therapy senam yoga 4 responden mengalami penurunan skala nyeri dari 5 menjadi 4 .

g. Hasil Penerapan Ketujuh

Tabel 8

Skala Nyeri Sendi karakteristik Responden $(n=4)$ Sebelum dan SesudahTherapy Senam Yoga di Rw 01 Kelurahan Kedoya Selatan

Kecamatan Kebon Jeruk Jakarta Barat 2021

\begin{tabular}{ccccc}
\hline & Responden & $\begin{array}{c}\text { Sebelum } \\
\text { Therapy } \\
\text { Senam Yoga }\end{array}$ & $\begin{array}{c}\text { Sesudah } \\
\text { Therapy } \\
\text { Senam Yoga }\end{array}$ & Keterangan \\
\hline $\begin{array}{c}\text { Senin, 2 } \\
\text { Agustus 2021 }\end{array}$ & $\begin{array}{c}\text { Responden 1 } \\
\text { Pukul 09.00 }\end{array}$ & 5 & 4 & $\begin{array}{c}\text { Nyeri berkurang } \\
\text { Turun }\end{array}$ \\
$\begin{array}{c}\text { Pertemuan } \\
7\end{array}$ & $\begin{array}{c}\text { Responden 2 } \\
\text { Pukul 10.10 }\end{array}$ & 5 & 4 & $\begin{array}{c}\text { Nyeri masih ada } \\
\text { Turun }\end{array}$ \\
& $\begin{array}{c}\text { Responden 3 } \\
\text { Pukul 11.15 }\end{array}$ & 4 & 3 & $\begin{array}{c}\text { Nyeri masih ada } \\
\text { Turun }\end{array}$ \\
& $\begin{array}{c}\text { Responden 4 } \\
\text { Pukul 12.30 }\end{array}$ & 4 & 3 & $\begin{array}{c}\text { Nyeri masih ada } \\
\text { Turun }\end{array}$
\end{tabular}

Sumber : Data Primer, 2021

Berdasarkan tabel 8 diatas menunjukan bahwa dari 4 responden sebelum therapy senam yoga pengukuran skala nyeri sendi rerata diatas 4. Setelah dilakukan herapy senam yoga 4 responden mengalami penurunan skala nyeri sendi dan nyeri berkurang pada hari ketujuh.

h. Hasil Penerapan Kedelapan

Tabel 9

Skala Nyeri Sendi karakteristik Responden $(n=4)$ Sebelum dan SesudahTherapy Senam Yoga di Rw 01 Kelurahan Kedoya Selatan Kecamatan Kebon Jeruk Jakarta Barat 2021

$\begin{array}{cccc}\text { Responden } & \begin{array}{c}\text { Sebelum } \\ \text { Therapy }\end{array} & \begin{array}{c}\text { Sesudah } \\ \text { Therapy }\end{array} & \text { Keterangan } \\ & \text { Senam Yoga } & \text { Senam Yoga } & \end{array}$




\begin{tabular}{ccccc}
\hline $\begin{array}{l}\text { Rabu, 4 } \\
\text { Agustus } \\
2021\end{array}$ & $\begin{array}{c}\text { Responden 1 } \\
\text { Pukul 09.00 }\end{array}$ & 4 & 3 & $\begin{array}{c}\text { Nyeri berkurang } \\
\text { Turun }\end{array}$ \\
$\begin{array}{c}\text { Pertemuan } \\
7\end{array}$ & $\begin{array}{c}\text { Responden 2 } \\
\text { Pukul 10.10 }\end{array}$ & 4 & 3 & $\begin{array}{c}\text { Nyeri masih ada } \\
\text { Turun }\end{array}$ \\
& $\begin{array}{c}\text { Responden 3 } \\
\text { Pukul 11.15 }\end{array}$ & 3 & 2 & $\begin{array}{c}\text { Nyeri masih ada } \\
\text { Turun }\end{array}$ \\
& $\begin{array}{c}\text { Responden 4 } \\
\text { Pukul 12.30 }\end{array}$ & 3 & 2 & $\begin{array}{c}\text { Nyeri masih ada } \\
\text { Turun }\end{array}$ \\
\hline
\end{tabular}

Hasil penelitian table 9 diatas menunjukan bahwa dari 4 responden sebelum therapy senam yoga pengukuran skala nyeri sendi rerata

\section{PEMBAHASAN}

Hasil pertama analisis terapi senam yoga menunjukkan bahwa dari 4 responden sebelum dilakukan senam yoga rerata nilaiskala nyeri 6 . Setelah dilakukan terapi senam yoga tidak mengalami penurunan skala nyeriyang signifikan pada hari pertama dan nyeri masih ada pada hari pertama. Hasil penelitian sebelumnya mengatakan Faradillah Fenty (2019) menunjukkan bahwa sebelum diberikan senam yoga hampir seluruhnya $(92,1 \%)$ atau 35 responden mengalami nyeriberat dan setelah melakukan senam yoga 19 responden merasakan nyeri ringan.

Hari kedua menunjukanbahwa dari 4 responden sebelum therapy senam yoga pengukuran skala nyeri sendi rata-rata diatas. Setelah dilakukan therapy senam yoga tidak mengalami penurunan yang signifikan skala nyeri sendi dan nyeri masih ada pada hari kedua. Hasil penelitian sebelumnya mengatakan Wulandari N.A, (2016) sebelum lansia mengikuti senam yoga $80 \%$ merasakan nyeri sendi dengan skala sedang setelah diatas 3. Setelah dilakukan therapy senam yoga 4 responden mengalami penurunan skalanyeri sendi dan nyeri berkurang pada hari kedelapan.

mengikuti yoga $50 \%$ lansia merasakan rasa nyeri sendi nya berkurang. Hari ketiga menunjukan bahwa dari 4 responden sebelum therapy senam yoga pengukurannilai pengukuran skala nyeri rerata diatas 5. Setelah dilakukan therapy senam yoga responden 1 yang mengalami penurunan skala nyeri dari 6 menjadi 5 , responden 3 mengalami penurunan skala nyeri dari 6 menjadi 5 dan responden 4 mengalami penurunan skala nyeri dari 6 menjadi 5 nyeri masih ada pada hari ketiga. Hari keempat menunjukan bahwa dari 4 responden sebelum therapy senam yoga pengukuran skala nyeri rerata diatas 5. Setelah dilakukan therapy senam yoga responden 1 yang mengalami penurunan skala nyeri dari 6 menjadi 5 , responden 2 mengalami penurunan skala nyeri sendi dari 6 menjadi 5 dan responden 4 mengalami penurunan dari 6 menjadi 5 nyerimasih ada pada hari keempat.

Hari kelima menunjukan bahwa dari 4 responden sebelum therapy senam yoga pengukuran skala nyeri sendi rerata 5 . Setelah dilakukan 
therapy senam yoga responden yang mengalami penurunan skala nyeri dari 5 menjadi 4 dan responden 4 mengalami penurunan skala nyeri dari 5 menjadi 4 masih ada pada hari kelima.

Berdasarkan penelitian Nugroho \&Sari, (2016) masyarakat yang belum melakukan senam yoga rata- rata intesitas nyeri 4,9 dan setelah melakukan senam yoga ratarata nyeri 3,8 sehingga mengalami rata-rata penurunan 1,1.

Hari keenam menunjukan bahwa dari 4 responden sebelum therapy senam yoga pengukuran skala nyeri sendi rerata 5 . Setelah dilakukan therapy senam yoga 4 responden mengalami penurunan skala nyeri dari 5 menjadi 4 dan nyeri masih ada pada hari keenam.

Hari ketujuh menunjukan bahwa dari 4 responden sebelum therapy senam yoga pengukuran skala nyeri sendi rerata diatas 4 . Setelah dilakukan therapy senam yoga 4 responden mengalami penurunan skala nyeri sendi dannyeri berkurang pada hari ketujuh. Hasil penelitian sebelumnya mengatakanFauziah M.R, (2020) hasilnya terjadi penurunan nyeri yang signifikan dengan nilai signifikan pada kelompok 1 (Yoga) $p=$ $0.011 \quad(p<0.05)$ dan penurunan nyeripada kelompok (Tai Chi) dengan nilai signifikan $p=0.011 \quad(p<0.05)$. Penelitian ini menunjukkan bahwa senam yoga dan senam tai chi samasama dapat menurunkan nyeri osteoarthritis lutut.

Hari kedelapan menunjukan bahwa dari 4 responden sebelum therapy senam yoga pengukuran skala nyeri sendi rerata diatas 3. Setelah dilakukan therapy senam yoga 4 responden mengalami penurunan skalanyeri sendi dan nyeri berkurang pada hari kedelapan. Hal ini menunjukkan bahwa semakin sering melakukan terapi senam yoga dapat mempengaruhiperubahan skala nyeri pada penderita nyeri sendi. Hasil penelitian sebelumnya mengatakan Istianah et.,al (2020). Menunjukkan bahwa setelah dilakukan senam yoga kombinasi open kinetic chain exercise menggunakan music keroncong dengan jumlah sample 43 orang. Dalam kategori nyeri ringan sebanyak 24orang $(55,8 \%)$ sebelum senam dan sesudah senam bertambahmenjadi 28 orang $(65,1 \%)$. Hal ini menunjukkan adanya penurunan nyeri setelah dilakukan senam yoga.

\section{KESIMPULAN}

Penerapan intervensi therapy senam yoga berpengaruh terhadap penilaian skala nyeri, dibuktikan dengan data karakteristik penderita nyerisendi yaitu usia, jenis kelamin, dan aktivitas. Faktor jarang berolahraga, tidak latihan berulang, merupakan salah satu faktor yang menyebabkan kekakuan dan nyeri sendi. Penerapan intervensi therapy senam yoga pada pasien nyeri sendi terjadi penurunan pada skala nyeri sendi, mulai dari nilai skala nyeri 6 sedang menjadi 5 dan skala 5 menjadi 4 hingga pada hari kedelapan responden 1 dan 2 dengan skala 3 ringan, dan responden 3 dan 4 dengan skala 2 ringan. Berdasarkan hal tersebutterjadi penurunan skala yang signifikan Perubahan skalanyeri pada lansia nyeri sendi setelah diberikan therapy senam yoga, hal ini menunjukkan bahwa semakin sering melakukan therapy senam yoga dapat mempengaruhi nila skala nyeri pada 
penderita nyeri sendi.

\section{SARAN}

Saran Bagi Pengambil Kebijakan

Kesehatan,

$\begin{array}{ccr}\text { Bagi } & \text { Puskesmas } & \text { Kelurahan } \\ \text { Kedoya } & \text { Selatan } & \text { dapat }\end{array}$

mempertimbangkan untukmelakukan intervensi Senam Yoga ini

sebagai

penatalaksanaan pasien nyeri sendi dalam program pelayananpuskesmas.

Bagi Institusi Pendidikan Keperawatan

Dapat memberikan informasi menjadi acuan intervensi keperawatan Senam Yoga untuk masalah kesehatan lansia khususnya penderita nyeri sendi, metode Senam Yoga dapat menjadi salah satu bahan materi yang dapat di berikan bagi mahasiswa untuk memperluas wawasan dalam intervensi keperawatan gerontik khususnya pada lansia penderita nyeri sendi.

Bagi Peneliti Selanjutnya

Perlu adanya penambahan proses intervensi Senam Yogadalam rangka pengembangan dan penyempurnaan intervensi keperawatan dalam mencegah penderita nyeri pada lansia.

Bagi Keluarga dan Lansia

Melanjutkan pengelolaan lansia secara mandiri guna mempertahankan kualitas hidupnya dan keluarga terus mendampingi

ntuk melanjutkan intervensi Senam Yoga sebagai upaya pencegahan penderita nyeri sendi pada lansia.
DAFTAR PUSTAKA

Anderson \& MC. Farlane. (2015). Peran Perawat

Komunitas.Kementerian Kesehatan RI: Keperawatan Keluarga dan Komunitas.

Azizah, Ma'rifatul.(2017). Keperawatan Lanjut Usia.Yogyakarta:Graha Ilmu.

Basuki, H. (2017). Pengaruh penelitian suatu pendekatan praktik.Jakarta: Rineka Cipta.

Dinas Kependudukan dan Pencatatan Sipil DKI Jakarta.(2019). Data Penduduk Lansia Berdasarkan Kecamatan dan Kelurahan. Diakses 20

Oktober 2020 dari https://data.jakarta.go.id

Faradillah Fenty.(2019). Pengaruh Senam Yoga Terhadap Tingkat Nyeri Rhematoid Arthritis Pada Lansia. Jogorot: Jombang.

Handono.(2013). Upaya Menurunkan Keluhan Nyeri Sendi Lutut pada Lansia di Posyandu Lansia Sejahtera.Jurnal Stikkes, Vol.6 No.1.

Handono. (2013). Pengertian Nyeri Sendi. JurnalStikkes. Vol.6 No.1

Herdiansyah. (2015). PenelitianCase Study Design. Sorong.

Hidayat, A. A (2014). Metode Penelitian Keperawatan dan Teknik Analisis Data. Jakarta: Salemba Medika.

Istianah et.,al.(2020).Kombinasi Senam Yoga dengan Open Exerchise Menggunakan Musik Keroncong untuk Menurunkan Nyeri Rhematoid Arthritis di Desa Mekar Sari, Narmada Lombok Barat,Journal of Community Engagement in Health.Vol 3 No.1.

Kadacha et.,al. (2016). Effect of Yogasana on

Balance 

Ppopualtion.International Journal
of
Physiothera
pyand Research, Vol.4(2):1401-
07.

Kemenkes Republik Indonesia. (2017). Prinsip Etik Penelitian Di Bidang Kesehatan. Jakarta:Indonesia.

Kemenkes Republik Indonesia.(2018). Pevalensi Penyakit Nyeri Sendi. Jakarta: Indonesia.

Maulana Nova. (2019). Pengaruh Terapi Yoga Pranayama Dan Aromatherapy Terhadap Penurunan Tingkat Nyeri Rheumatoid Arthritis Pada Lansia. Yogyakarta.

Nugroho \& Sari.(2016). Senam Yoga Untuk Menurunkan Intensitas Nyeri Pada Penderita Osteoarthritis diWilayah Kerja
Puskesmas Babat Lamongan.Vol.2 No. 2.

Safarina \& Dewi. (2018). Pengaruh Senam Yoga Terhadap Skala Nyeri Low Back Pain (LBP) Pada Dewasa Menengah. Cimahi Tengah.

Solehati $T$ dan Kosasih $E$. (2015).Konsep dan Aplikasi Relaksasi Dalam Keperawatan Maternitas.Edisi 1 Bandung: PT Refika Aditama.

Wulandari N.A. (2016). Pengaruh YogaTerhadap Nyeri Sendi Pada Lansia di Pslu Blitar.Jurnal Ners dan Kebidanan. Vol. 3 No. 3.

World Health Organization (WHO). (2016). Global Healt Observatory (GHO)Data.

World Health Organization (WHO.(2018).Ageing and Health. 